\title{
A Concept for Selection of Codon-Suppressor tRNAs Based on Read-Through Ribosome Display in an In Vitro Compartmentalized Cell-Free Translation System
}

\author{
Atsushi Ogawa, ${ }^{1,2}$ Masayoshi Hayami, ${ }^{1}$ Shinsuke Sando, ${ }^{1,3}$ and Yasuhiro Aoyama ${ }^{1,4}$ \\ ${ }^{1}$ Department of Synthetic Chemistry and Biological Chemistry, Graduate School of Engineering, Kyoto University, Katsura, \\ Nishikyo-ku, Kyoto 615-8510, Japan \\ ${ }^{2}$ Ehime University, 3 Bunkyo-cho, Matsuyama, Ehime 790-8577, Japan \\ ${ }^{3}$ INAMORI Frontier Research Center, Kyushu University, 744 Motooka, Nishi-ku, Fukuoka 819-0395, Japan \\ ${ }^{4}$ Department of Molecular Chemistry and Biochemistry, Faculty of Science and Engineering, Doshisha University, \\ 1-3 Tatara-Miyakodani, Kyotanabe, Kyoto 610-0321, Japan
}

Correspondence should be addressed to Atsushi Ogawa, a-ogawa@ccr.ehime-u.ac.jp

and Shinsuke Sando, ssando@ifrc.kyushu-u.ac.jp

Received 30 May 2012; Accepted 29 June 2012

Academic Editor: Masayasu Kuwahara

Copyright (C) 2012 Atsushi Ogawa et al. This is an open access article distributed under the Creative Commons Attribution License, which permits unrestricted use, distribution, and reproduction in any medium, provided the original work is properly cited.

\begin{abstract}
Here is presented a concept for in vitro selection of suppressor tRNAs. It uses a pool of dsDNA templates in compartmentalized water-in-oil micelles. The template contains a transcription/translation trigger, an amber stop codon, and another transcription trigger for the anticodon- or anticodon loop-randomized gene for $\mathrm{tRNA}^{\mathrm{Ser}}$. Upon transcription are generated two types of RNAs, a tRNA and a translatable mRNA (mRNA-tRNA). When the tRNA suppresses the stop codon (UAG) of the mRNA, the full-length protein obtained upon translation remains attached to the mRNA (read-through ribosome display) that contains the sequence of the tRNA. In this way, the active suppressor tRNAs can be selected (amplified) and their sequences read out. The enriched anticodon (CUA) was complementary to the UAG stop codon and the enriched anticodon-loop was the same as that in the natural tRNA $^{\text {Ser }}$.
\end{abstract}

\section{Introduction}

Selection/amplification is a general tool for directed evolution of nucleic acids and proteins [1], which is much more complicated for reaction promoters (biocatalysts) than for simple binders [2]. Selection and identification for the former require some sort of catalyst-product pairing in an isolated compartment. In vivo selection using living cells has been typical choice for such a purpose. Meanwhile, in vitro selection, as opposed to in vivo selection, is simple and convenient to carry out, is free from cytotoxicity problems, and allows for starting with a library of great diversity.

Griffiths and Tawfik proposed an in vitro compartmentalization (IVC) technique for the in vitro evolution of biomolecules including biocatalysts, where biocatalysts are transcribed/translated in a compartmentalized water-in-oil emulsion to allow catalyst-product pairing [2]. In practice, the IVC technique has been applied successfully for evolving or improving biocatalysts such as ribozymes and enzymes [3-12].

Here, we applied the IVC technique for evolution of tRNAs (one of catalysts in protein translation systems) [1316] and present a promising concept for in vitro selection of suppressor tRNAs by the combination of read-through ribosome display (Rt-RD, vide infra) $[17,18]$.

\section{Materials and Methods}

2.1. General Design, Transcription/Translation System, and Analysis. Biological reagents and solvents were purchased from standard suppliers and used without further purification. Binding of suppressor tRNA to an amber stop codon is in competition with that of release factor 1 (RF1) to 
terminate the translation. The amber codon is also often misread by the exogenous tRNA for Gln. To maximize the suppression efficiency and minimize incorporation of Gln at the amber codon, we used a reconstituted prokaryotic cell-free translation system (PURESYSTEM Classic) [19], in which RF1, and Gln and Gln-tRNA synthetase had not been added unless otherwise stated. The T7-promoted translation is generally more efficient for longer templates. To keep a "balance" in the amounts of the fused mRNA (mRNA-tRNA) (longer) and the tRNA (shorter) transcribed, we put GCC immediately downstream of the first T7-promoter so as to lower the translation efficiency for the fused mRNA (It is known that a G-less sequence, immediately downstream of the T7 promoter, suppresses the transcription efficiency). Gel electrophoresis and blotting were carried out on a BE-250 electrophoresis apparatus (BIO CRAFT) and a Trans-Blot SD system (Bio-Rad), respectively.

2.2. Preparation of Template DNAs for Selection. pDHFR, encoding E. coli DHFR, was a gift from Dr. Y. Shimizu. The first PCR was carried out in $20 \mu \mathrm{L}$ of a reaction mixture containing 4 pmol of a forward primer containing a FLAG domain (bold) and a TAG amber stop codon (italic) $5^{\prime}$-d(AA GGA GAT ATA CCA ATG GAC TAC AAG GAT GAC GAT GAC AAG TAG ATC AGT CTG ATT GCG GCG TTA G)$3^{\prime}, 4$ pmol of a reverse primer with the lower $\mathrm{T} 7$ promoter (underlined) 5'-d(GTT CAG CCG CTC CGG CAT CTC TCC TAT AGT GAG TCG TAT TAC CGG GTG ACT GCT GAG GA)-3' for the tRNA-fused template or $5^{\prime}$-d(TGG CGG AGA GAG GGG GAT TTG AAC CGG GTG ACT GCT GAG GA) $-3^{\prime}$ for nonfused template, $20 \mathrm{ng}$ of pDHFR, $1.25 \mathrm{U}$ of Pfu Ultra HF DNA polymerase (Stratagene), $4 \mathrm{nmol}$ each of dNTPs (TOYOBO), and $2 \mu \mathrm{L}$ of $10 \times$ Pfu Ultra HF reaction buffer. After the PCR reaction, the product was purified by agarose gel electrophoresis. The second PCR was carried out in $20 \mu \mathrm{L}$ of a reaction mixture containing $4 \mathrm{pmol}$ of a forward primer with the upper T7 promoter (underlined) and the following sequence after modification (vide supra) of the widely-used one $5^{\prime}$-d (T AAT ACG ACT CAC TAT AGC CCG GCC ACA ACG GCT GGG CTC TAG AAA TAA TTT TGT TTA ACT TTA AGA AGG AGA TAT ACC A)-3', 4 pmol of a reverse primer with the sequence for $E$. coli tRNA for Ser (SerU) 5' -d(TGG CGG AGA GAG GGG GAT TTG AAC CCC CGG TAG AGT TGC CCC TAC TCC GGT $\mathrm{L}_{1} \mathrm{~L}_{2} \mathrm{X} \mathrm{YZL}_{3}$ $\mathrm{L}_{4}$ AC CGG TCC GTT CAG CCG CTC CGG CAT C)-3' ( $\mathrm{L}_{1 \sim 4}$ and $\mathrm{XYZ}$ represent the anticodon-loop and anticodon bases, respectively), $\sim 20 \mathrm{fmol}$ of the purified first PCR product, $1.25 \mathrm{U}$ of Pfu Ultra HF DNA polymerase, $4 \mathrm{nmol}$ each of dNTPs, and $2 \mu \mathrm{L}$ of $10 \times P f u$ Ultra HF reaction buffer.

2.3. In Vitro Selection of Suppressor tRNAs. In vitro coupled transcription/translation of template DNAs in the reversephase micelle was carried out as follows. A $50 \mu \mathrm{L}$ portion of a cell-free translation system containing $50 \mathrm{pM}$ of a DNA template $(2.5 \mathrm{fmol})$ was added gradually to $950 \mu \mathrm{L}$ of mineral oil (Sigma) containing detergents Span 85 (Nacalai Tesque) $(4.5 \% \mathrm{v} / \mathrm{v})$ and Tween 20 (Sigma) $(0.6 \% \mathrm{v} / \mathrm{v})$ under stirring on ice. The diameter $(d)$ of the micelles (water droplets) in the resulting emulsion was about $2 \mu \mathrm{m}$, indicating that the number of micelles was $N=V / v=1.2 \times 10^{10}$, where $V$ is the total volume of the water phase $(50 \mu \mathrm{L})$ and $v$ is the volume of a micelle with $d=2 \mu \mathrm{m}$. The dsDNA used ( $2.5 \mathrm{fmol})$ contains $1.5 \times 10^{9}$ template molecules. This number is one-order of magnitude smaller than that of the micelles. Thus, each micelle is expected to encapsulate maximally one template.

After incubation of the mixture at $37^{\circ} \mathrm{C}$ for $1 \mathrm{~h}$, the emulsion was spun at $2000 \times \mathrm{g}$ for $10 \mathrm{sec}$. A $200 \mu \mathrm{L}$ portion of the supernatant was carefully taken from the upper part and mixed with $200 \mu \mathrm{L}$ of an ice-cold selection buffer (Phosphate-K, pH 7.3) containing $92.2 \mathrm{mM}$ of $\mathrm{K}^{+}, 300 \mathrm{mM}$ of $\mathrm{Na}^{+}, 50 \mathrm{mM}$ of $\mathrm{Mg}^{2+}, 0.05 \%$ of Tween 20 (WAKO), $2 \%$ of Block Ace (Dainippon Pharmaceutical Co.), and $1 \mathrm{~mL}$ of ice-cold water-saturated ether. The mixture was inverted twenty times and centrifuged at $16100 \times \mathrm{g}$ for $10 \mathrm{~min}$ at $4^{\circ} \mathrm{C}$, and then the organic ether phase was removed. The water phase was washed with $1 \mathrm{~mL}$ of ether and mixed with $200 \mu \mathrm{L}$ of ice-cold selection buffer. The mixture was applied on a column packed with prewashed anti-FLAG M2 agarose (Sigma) and gently inverted for $2 \mathrm{~h}$ at $4^{\circ} \mathrm{C}$. After washing the gel retaining the ribosome-protein-mRNA (PRM) complex with $200 \mu \mathrm{L}$ of selection buffer five times, the mRNAs were eluted upon collapse of the RPM complexes with $200 \mu \mathrm{L}$ of an elution buffer (Phosphate-K, pH 7.2) containing $92.2 \mathrm{mM}$ of $\mathrm{K}^{+}, 300 \mathrm{mM}$ of $\mathrm{Na}^{+}, 30 \mathrm{mM}$ of EDTA, $0.05 \%$ of Tween 20, and 2\% of Block Ace. The mRNAs eluted were purified with an RNeasy MinElute Cleanup Kit (QIAGEN) and amplified with a QIAGEN One-Step RT-PCR Kit according to the manufacture's protocol using a forward primer with T7 promoter (underlined) and a FLAG domain (bold) followed by a TAG amber stop codon (italic) $5^{\prime}-\mathrm{d}$ (T AAT ACG ACT CAC TAT AGC CCG GCC ACA ACG GCT GGG CTC TAG AAA TAA TTT TGT TTA ACT TTA AGA AGG AGA TAT ACC A ATG GAC TAC AAG GAT GAC GAT GAC AAG TAG) $-3^{\prime}$ and a reverse primer $5^{\prime}$-d(TGG CGG AGA GAG GGG GAT TTG AAC CCC CGG TAG AGT TGC C)-3'. The resulting RT-PCR products were used for the next round of selection and, after three (for anticodon-randomized tRNA) or five (for anticodonloop-randomized tRNA) rounds, were monocloned using a PCR Cloning Kit (QIAGEN) and sequenced. Single-round coupled transcription/translation under normal (noncompartmentalized) or compartmentalized conditions (referring to Figure 1(b), lanes 1-4 or 5, resp.) was carried out using $400 \mathrm{pM}$ of a template in $25 \mu \mathrm{L}$ of a cell-free translation system under otherwise identical conditions.

\subsection{Preparation of Nonfused Template mRNAs for Western} Blotting. The first PCR was carried out in $20 \mu \mathrm{L}$ of a reaction mixture containing 4 pmol of a forward primer with a FLAG domain (bold) with or without a TAG amber stop codon (italic) $5^{\prime}$-d(AA GGA GAT ATA CCA ATG GAC TAC AAG GAT GAC GAT GAC AAG [TAG] ATC AGT CTG ATT GCG GCG TTA G)-3', 4 pmol of a reverse primer with an ochre stop codon (italic) $5^{\prime}$-d(TAT TCA TTA CCG CCG CTC CAG AAT CT)-3', $20 \mathrm{ng}$ of pDHFR, $1.25 \mathrm{U}$ of Pfu Ultra HF DNA polymerase (Stratagene), $4 \mathrm{nmol}$ each of 


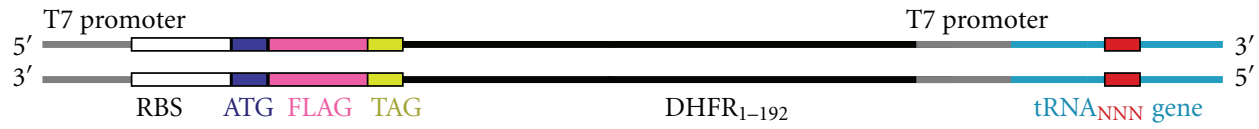

(a)

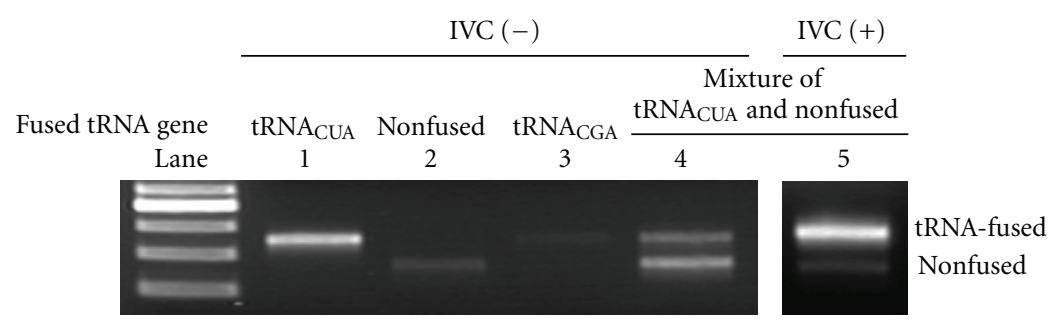

(b)

FIgure 1: (a) Schematic sequence of the tRNA-fused template with two T7 promoters. The triple N in red represents the anticodon- or anticodon-loop-randomized region. (b) Agarose gel electrophoretic assay of the template DNAs recovered from tRNA CUA $_{\text {-fused }}$ template

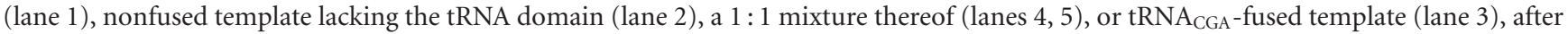
coupled transcription/translation under normal (noncompartmentalized) (lanes 1-4) or compartmentalized (lane 5) conditions.

dNTPs (TOYOBO), and $2 \mu \mathrm{L}$ of $10 \times$ Pfu Ultra HF reaction buffer. After the PCR reaction, the product was purified by agarose gel electrophoresis. The second PCR was carried out in $20 \mu \mathrm{L}$ of a reaction mixture containing $4 \mathrm{pmol}$ of a forward primer with T7 promoter (underlined) $5^{\prime}-\mathrm{d}(\mathrm{GAA}$ ATT AAT ACG ACT CAC TAT AGG GAG ACC ACA ACG GTT TCC CTC TAG AAA TAA TTT TGT TTA ACT TTA AGA AGG AGA TAT ACC A)-3', 4 pmol of a reverse primer $5^{\prime}$-d(TAT TCA TTA CCG CCG CTC CAG AAT CT)-3', $\sim 20 \mathrm{fmol}$ of the purified first PCR product, $1.25 \mathrm{U}$ of $\mathrm{Pfu}$ Ultra HF DNA polymerase, $4 \mathrm{nmol}$ each of dNTPs, and $2 \mu \mathrm{L}$ of $10 \times P f u$ Ultra HF reaction buffer. Template mRNAs were obtained by run-off transcription of the $5^{\prime}$-FLAGTAG-DHFR or 5'-FLAG-DHFR template DNA obtained using a T7-MEGAshortscript Kit (Ambion). Thus, a T7transcription mixture $(10 \mu \mathrm{L})$ containing $3 \mu \mathrm{L}$ of the PCR solution of template DNA was incubated at $37^{\circ} \mathrm{C}$ for $2 \mathrm{~h}$. After addition of $1 \mathrm{U}$ of DNase I, the mixture was incubated for additional $15 \mathrm{~min}$. mRNAs were purified with an RNeasy MinElute Cleanup Kit (QIAGEN) and concentrations of the purified specimens were determined by the absorbance at $260 \mathrm{~nm}$.

2.5. Preparation of $\mathrm{tRNA}_{\text {L1L2XYZl3L4. E. coli }}^{\mathrm{SerU}}$ tRNA $^{\text {SerU }}$ L1L2XYZL3L4 was prepared by run-off in vitro transcription. Template DNA was prepared by PCR in $20 \mu \mathrm{L}$ of a reaction mixture containing $20 \mathrm{pmol}$ of a forward primer with T7 promoter (underlined) $5^{\prime}-\mathrm{d}(\mathrm{G}$ TAA TAC GAC TCA CTA TA GGA GAG ATG CCG GAG CGG CTG AAC)-3', 20 pmol of a reverse primer $5^{\prime}$-d(TGG CGG AGA GAG GGG GAT TTG AAC CCC CGG TAG AGT TGC C)-3', $100 \mathrm{fmol}$ of a template DNA (initial, RT-PCR amplified, or monocloned), 1.25 U of Pfu Ultra HF DNA polymerase (Stratagene), $10 \mathrm{nmol}$ each of dNTPs (TOYOBO), and $2 \mu \mathrm{L}$ of $10 \times P f u$ Ultra HF reaction buffer. The resulting PCR solution was used for transcription using a T7-MEGAshortscript Kit (Ambion) for $37^{\circ} \mathrm{C}$ for $20 \mathrm{~h}$. The transcribed tRNAs were purified by denaturing PAGE $(8 \%)$, followed by ethanol precipitation and, after dissolution in $500 \mu \mathrm{L}$ of water, further by passing successively through Microcon YM-30 (Millipore) and G-25 Microspin Columns (Amersham). Concentrations of the purified tRNAs were determined by the absorbance at $260 \mathrm{~nm}$.

2.6. Translation of $m R N A$ and Western Blotting Analysis with Exogenous tRNAs. Translation of a template mRNA ( $5^{\prime}$-FLAG-UAG-DHFR or $5^{\prime}$-FLAG-DHFR as a UAG $(-)$ positive control) $(2 \mu \mathrm{g})$ was carried out at $37^{\circ} \mathrm{C}$ for $1 \mathrm{~h}$ in the presence of an exogenous tRNA $(2 \mu \mathrm{g})$ in $10 \mu \mathrm{L}$ of a reconstituted cell-free translation system, in which RF1 had not been added, but Gln and Gln-tRNA synthetase had. To the reaction mixture were added $165 \mu \mathrm{L}$ of water and $175 \mu \mathrm{L}$ of a sample-loading buffer (125 mM Tris-HCl ( $\mathrm{pH} 6.8$ ), 4\% $(\mathrm{w} / \mathrm{v})$ SDS, 20\% (w/v) glycerol, 0.002\% (w/v) bromophenol blue, and $10 \%(\mathrm{v} / \mathrm{v})$ 2-mercaptoethanol). The resulting solution was incubated at $95^{\circ} \mathrm{C}$ for $5 \mathrm{~min}$ and applied on 15\% SDS-PAGE. Western blotting was performed on a PVDF membrane (Hybond-P, Amersham). FLAG-tagged proteins were visualized with anti-FLAG-HRP conjugate (Sigma) and ECL Plus Western Blotting Detection Reagent (Amersham). The suppression efficiencies were evaluated by comparing the band intensities of the FLAG-TAG-DHFR protein, determined by using the Image J software (NIH), with those of serially diluted $(10,20,40,60,80,100 \%)$ solutions of the stop-free FLAG-DHFR reference protein translated under otherwise identical conditions.

\section{Results and Discussion}

We previously introduced Rt-RD [18], in which expressed protein could be fully displayed upon suppression of the stop codon(s) downstream of the open reading frame by appropriate suppressor tRNAs. In this paper, we conversely apply the Rt-RD technique for the selection of suppressor tRNAs that are coded at the 3 '-terminus of the very template that contains the stop codon to be suppressed. We prepared 
(b)

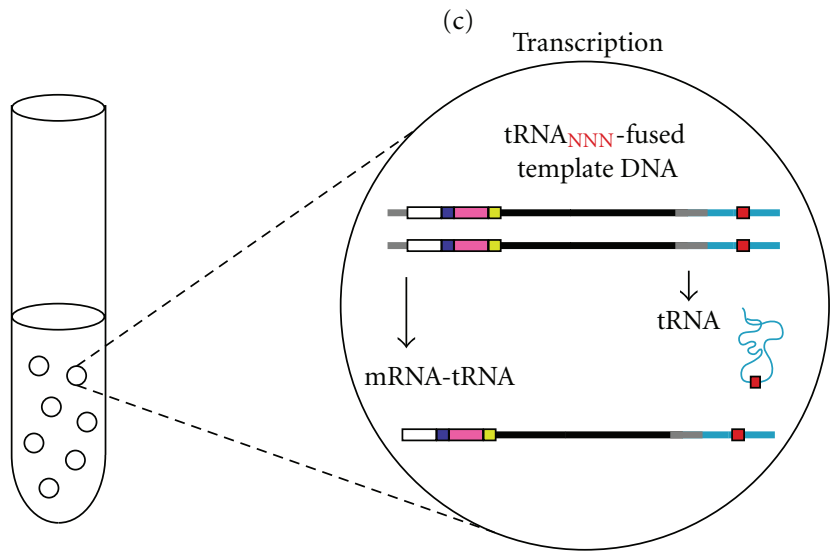

(one template per one micelle)

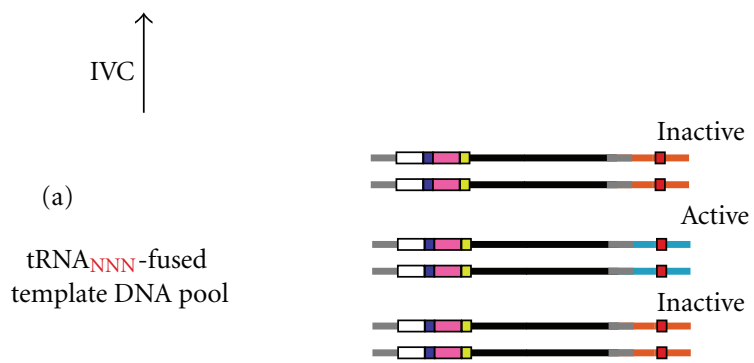

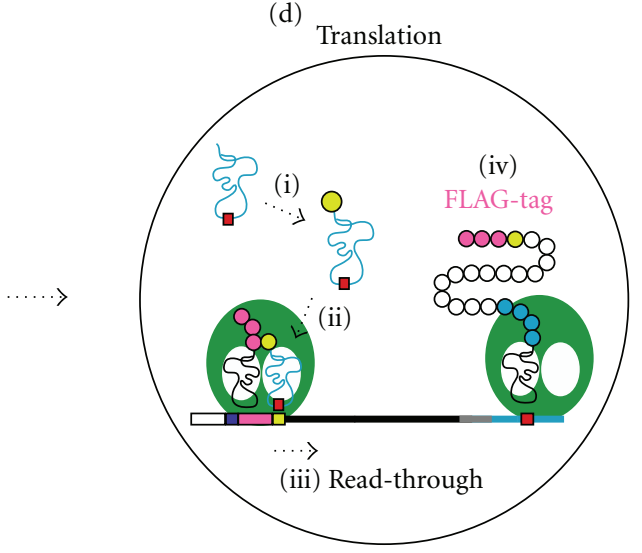

(1) Water/Mg ${ }^{2+}$, ether (2) Anti-FLAG antibody (3) EDTA

(e)

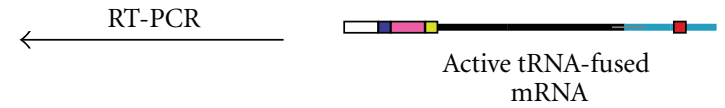

Figure 2: Rt-RD/IVC-based selection/amplification cycle. See the text for explanation.

a dsDNA template containing, under the control of a T7 promoter, the RBS (ribosome binding site), the ATG start codon, a FLAG domain, the TAG (amber) stop codon, and a spacer $\left(\mathrm{DHFR}_{1-192}\right)$ derived from the E. coli DHFR gene covering the amino acids 1-64, followed by the tRNA sequence together with its own T7 promoter (Figure 1(a)). There are two $\mathrm{T} 7$ promoters in this template, transcription of which thus generates two types of RNAs; the one that contains both an RBS and an AUG serves as an mRNA, and the other, which lacks them, serves only as a tRNA. When the latter (tRNA) happens to suppress (read through) the amber (UAG) stop codon in the transcribed mRNA, a fused protein containing the FLAG, DHFR $_{1-192}$, and tRNA regions would result upon translation and remain attached to the mRNA with the $\mathrm{DHFR}_{1-192}$-tRNA portion, serving as a spacer to be anchored in the ribosome tunnel to squeeze the FLAG-tag peptide for full display (Rt-RD; Figure 2).

We first confirmed that the right amber suppressor ( tRNA $^{\text {SerU }}$ CUA) generated in this way worked as such. The anticodon-adjusted (CUA) tRNA ${ }^{\text {SerU }}$ is known to be aminoacylated with Ser by endogenous Ser-tRNA synthetase and hence suppress (read through) the amber codon with concomitant incorporation of Ser at that position $[18,20]$. Coupled transcription/translation for $1 \mathrm{~h}$ of the template fused with the gene for tRNA ${ }^{\text {SerU }}{ }_{\text {CUA }}$ (Figure $1(\mathrm{a}), \mathrm{NNN}$ $=$ CUA) in a reconstituted prokaryotic (E. coli) cell-free translation system [19] containing T7 RNA polymerase was followed by affinity selection $\left(4^{\circ} \mathrm{C}\right.$ and $\left.\left[\mathrm{Mg}^{2+}\right]=50 \mathrm{mM}\right)$ of the FLAG-tag peptide domain displayed (Rt-RD) in the protein-ribosome-mRNA (PRM) complex. The mRNA template coding the $\mathrm{tRNA}^{\mathrm{SerU}}$ CUA sequence was recovered upon disruption of the ternary complex with EDTA, RTPCR amplified, and identified as such (Figure 1(b), lane 1). However, the template was by no means recovered efficiently when it was lacking (nonfused) the tRNA domain (lane 2) or fused with anticodon-mismatched (CGA) natural tRNA for Ser (NNN = CGA) (lane 3). (In respect to the weak spots seen in lanes 2 and 3 (Figure 1(b)), it is known that the stop codons can be suppressed to some extent (up to several \%) in an RF1-minus translation system by misreading even in the absence of a suppressor tRNA.) In these cases, there is no generation of the correct tRNA for amber suppression and hence translation stops at the amber (UAG) codon, giving rise only to the FLAG peptide with no linkage to the genotype (mRNA). Conversely, when equal amounts of nonfused (suppression irrelevant) and $\mathrm{tRNA}^{\mathrm{SerU}}{ }_{\mathrm{CUA}}$-fused (relevant) templates were used, both templates were recovered (lane 4) (In respect to the apparently stronger spot for the nonfused template in lane 4 (Figure $1(\mathrm{~b})$ ) , it is generally true that shorter templates are more easily amplified by PCR.) This is because suppressor tRNA ${ }^{\text {SerU }}$ CUA generated from the latter template can suppress the amber codon of the former. To avoid such a crossover, we needed to compartmentalize the reactions of each template using a water-in-oil emulsion system [3-12]. With this technique (see below, Figure 2), we could selectively recover the tRNA ${ }^{\text {SerU }}{ }_{\text {CUA-fused template }}$ coding the active suppressor tRNA (lane 5) from the above mixture.

We then moved on to the selection of suppressor tRNAs. The selection cycle is shown in Figure 2. An initial pool 


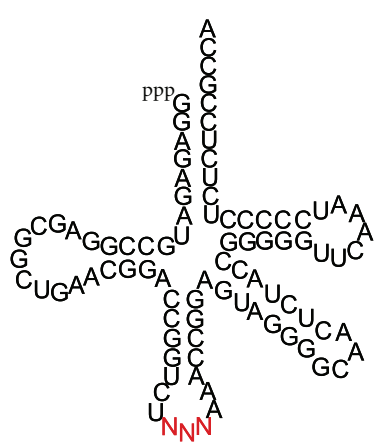

$E c$-tRNA $\mathrm{Ser}_{\mathrm{NN}}^{\mathrm{S}}$

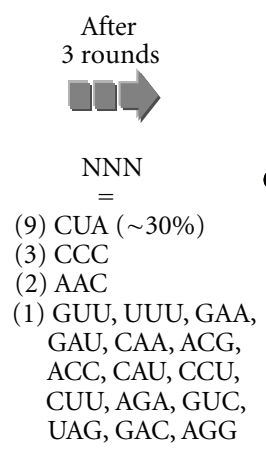

(total 29 clones)

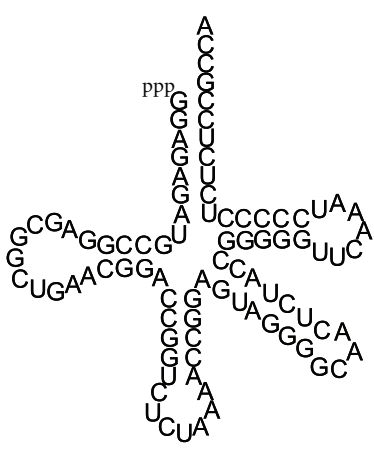

$E c$-tRNA $A_{\text {CUA }}^{\text {Ser }}$

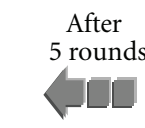

NN-[CUA]-NN

(15) CU-AA

10) CC-AA

(5) CU-AC

(4) UU-AC

(3) CC-AC

(1) GU-AC

UA-CA

(total 39 clones)

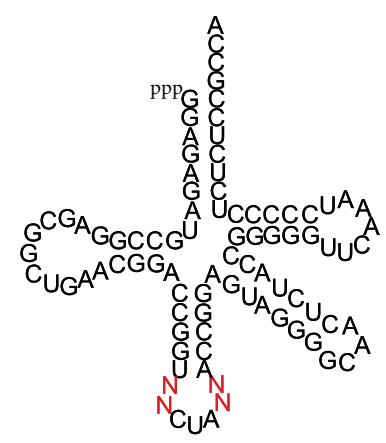

$E c$-tRNA $A_{N N C U A N N}^{\text {Ser }}$

(a)

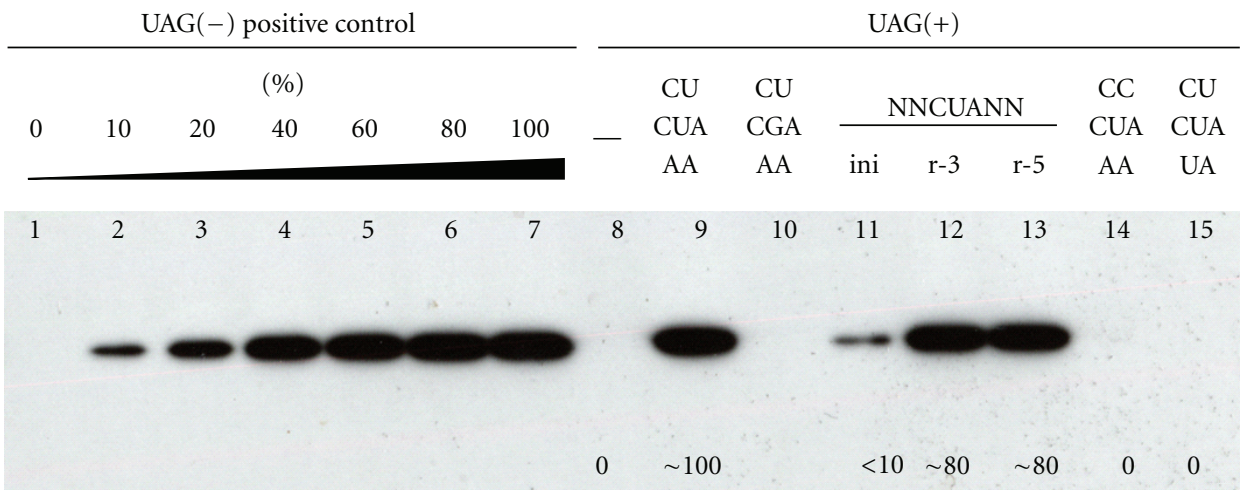

mRNA

tRNA $\quad\left(\begin{array}{c} \\ N_{32} N_{33} \\ N_{34} N_{35} N_{36} \\ N_{37} N_{38}\end{array}\right)$

Lane

Suppression

efficiency (\%)

(b)

FIGURE 3: (a) Summary of selection/amplification of anticodon-randomized or anticodon-matched/anticodon-loop-randomized tRNAs for Ser. The numbers of clones that possess the sequence shown are indicated in parentheses. (b) Western blotting analysis of the translation of nonfused (tRNA-lacking) mRNA templates under normal (noncompartmentalized) conditions with (lanes 9-15) or without (lane 8) tRNA; tRNA ${ }_{\text {CUA }}^{\text {SerU }}$ (lane 9), tRNA $^{\text {SerU }}{ }_{\text {CGA }}$ (natural tRNA for Ser, lane 10), anticodon-loop-randomized tRNA ${ }^{\text {SerU }}$ after 0, 3 , or 5 rounds of selection/amplification (lanes 11, 12, or 13, respectively), or anticodon-matched but singly loop-mutated tRNA ${ }^{\text {SerU }}$ (lanes 14 and 15). Lane 7 represents a control translation using amber-free mRNA with no use of tRNA as a positive control and lanes 1-7 are a calibration set.

(a) of fused templates (Figure $1(\mathrm{a}), \mathrm{NNN}=\mathrm{NNN}$ with a diversity of $4^{3}=64$ ) with genes for anticodon-randomized tRNA $^{\text {SerU }}$ (Figure 3(a), left) was subjected to coupled transcription/translation in a water-in-oil emulsion (b) [3-12]. Consequently, each compartment $(\sim 2 \mu \mathrm{m})$ generates and contains a pair of template-related sister RNAs, a fused mRNA (shown as mRNA-tRNA) and a tRNA (c). The whole protein, susceptible to Rt-RD in the form of a PRM complex (step iv in d), can be translated (d) only when the tRNA serves as an amber suppressor (steps i-iii in d). The ternary complex thus formed was recovered by affinity selection of the displayed FLAG tag after breaking the emulsion and treated with EDTA to afford the active tRNA-fused template mRNAs (e), which were purified and amplified by RT-PCR back to the dsDNA templates (a), for use in another selection cycle. The DNAs obtained after three such cycles were monocloned and sequenced. The anticodon of approximately one third of the 29 monocloned tRNAs was CUA (Figure 3(a), center), which was the one expected based on codon-anticodon complementarity. These results indicate that the sensitive PRM complex survives the IVC and workup conditions to allow the Rt-RD/IVC method to select suppressor tRNAs.

Finally, we applied the Rt-RD/IVC method to the engineering of the two-base loop regions adjacent to the anticodon. These regions are variant in various tRNAs but are believed to be important in stabilizing codonanticodon interactions [21]. Selection of fused templates with genes of anticodon-matched (CUA) and anticodonloop-randomized (NN-CUA-NN with a diversity of $4^{4}=256$ ) tRNA $^{\text {SerU }}$ (Figure 3(a), right) was carried out as above. DNA templates recovered after five cycles were monocloned and sequenced. Interestingly, $\sim 40 \%$ of the 39 monocloned tRNAs had the same loop sequence (CU-CUA-AA) as the natural tRNA for Ser (CU-CGA-AA) even in the base modificationfree conditions (Figure 3(a)). These results indicate that the anticodon-loop sequence itself has played a preserved or sophisticated role in the evolution of tRNAs that now have many modified bases (Since neither anticodon nor anticodon-loop region is recognized by the serenyl-tRNA 
synthetase [22], the selected loop sequence may play a role in stabilizing the interaction between the amber stop codon and the suppressor anticodon.) [22, 23]. Suppression efficiencies were evaluated by western blotting analysis using the nonfused template lacking the tRNA domain in an RF1-minus translation system under noncompartmentalized conditions (Figure 3(b)). Enrichment of active tRNA became notably pronounced after three rounds (lanes 11-13) (The reason for the high suppression efficiency $(\sim 80 \%)$ despite the low percentage amounts of the active tRNA ${ }^{\mathrm{SerU}}{ }_{\mathrm{CUA}}(10 \%$ in round 3 and $38 \%$ in round 5) is that excess amounts of tRNA ${ }^{\text {SerU }}{ }_{\text {CUA }}$ were used in the experiments for western blotting (Figure 3(b))) and the suppression efficiency of the

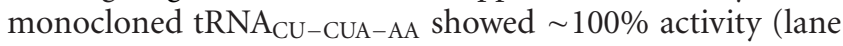
9) compared with the suppression-free translation using a UAG(-) reference template (lane 7). Interestingly, a single mutation in the anticodon-loop domain led to a dramatic loss of activity (lanes 14 and 15). This is in accord with the above argument.

In summary, a concept for in vitro selection of suppressor tRNAs is presented. An essential aspect of it is that tRNA is a part of mRNA (mRNA-tRNA fusion), being located downstream of the particular codon to be suppressed (the amber stop codon in this study). Therefore, only active tRNAs that can self-suppress the codon in a water-in-oil compartment are susceptible to amplification by the readthrough ribosome-display technique.

Although the concept was well demonstrated, the present method must be further optimized especially regarding the selection efficiencies. Three or five rounds of selection were required for enrichment from the small library sizes $(n=64$ and 256). One possible reason for this low selection efficiency is a misreading of stop codon in an RF1-minus translation system, which would result in the recovery of false positive tRNA-fused mRNAs. The misreading might be reduced by coexisting small amounts of RF-1. Another reason is the instability of RPM complex against extraction conditions. Optimization of extraction conditions or the use of mRNA display technique $[24,25]$ might overcome the instability. Of course, compartmentalization conditions or mRNA/tRNA ratios are also the factor to be checked.

Furthermore, it is not easy to understand that 10 clones out of $39(26 \%)$ had the CC-CUA-AA anticodon-loop sequence after 5 rounds (Figure 3(a)), which turned out to be completely inactive in suppression (Figure 3(b), lane 14). Taking into account the fact that the CC-CUA-AA occupies $25 \%$ of pool even in round 3 in contrast to the less percentage amounts of the active CU-CUA-AA sequence (10\%), it is feasible to speculate that the inactive CC-CUA-AA sequence might be already abundant in the initial pool and/or has been more easily amplified regardless of the selection process.

After sufficient improvements, the method may provide a promising in vitro tool for tRNA evolutions.

\section{Acknowledgments}

The authors thank Dr. N. Doi of Keio University and Dr. Y. Shimizu of RIKEN for advising as to IVC experiments and for providing the plasmid pDHFR, respectively. A.
Ogawa acknowledges a fellowship from the JSPS. This work was partly supported by The Sumitomo Foundation and partially supported by "Special Coordination Funds for Promoting Science and Technology" from the Ministry of Education, Culture, Sports, Science and Technology, the Japanese Government.

\section{References}

[1] D. S. Wilson and J. W. Szostak, "In vitro selection of functional nucleic acids," Annual Review of Biochemistry, vol. 68, pp. 611647, 1999.

[2] A. D. Griffiths and D. S. Tawfik, "Man-made enzymes—from design to in vitro compartmentalisation," Current Opinion in Biotechnology, vol. 11, no. 4, pp. 338-353, 2000.

[3] D. S. Tawfik and A. D. Griffiths, "Man-made cell-like compartments for molecular evolution," Nature Biotechnology, vol. 16, no. 7, pp. 652-656, 1998.

[4] N. Doi and H. Yanagawa, "STABLE: protein-DNA fusion system for screening of combinatorial protein libraries in vitro," FEBS Letters, vol. 457, no. 2, pp. 227-230, 1999.

[5] M. Levy, K. E. Griswold, and A. D. Ellington, "Direct selection of trans-acting ligase ribozymes by in vitro compartmentalization," RNA, vol. 11, no. 10, pp. 1555-1562, 2005.

[6] H. S. Zaher and P. J. Unrau, "Selection of an improved RNA polymerase ribozyme with superior extension and fidelity," RNA, vol. 13, no. 7, pp. 1017-1026, 2007.

[7] Y. Zheng and R. J. Roberts, "Selection of restriction endonucleases using artificial cells," Nucleic Acids Research, vol. 35, no. 11, article e83, 2007.

[8] B. T. Kelly and A. D. Griffiths, "Selective gene amplification," Protein Engineering, Design and Selection, vol. 20, no. 12, pp. 577-581, 2007.

[9] M. Levy and A. D. Ellington, "Directed evolution of streptavidin variants using in vitro compartmentalization," Chemistry and Biology, vol. 15, no. 9, pp. 979-989, 2008.

[10] Y. Chen, J. Mandic, and G. Varani, "Cell-free selection of RNAbinding proteins using in vitro compartmentalization," Nucleic Acids Research, vol. 36, no. 19, article e128, 2008.

[11] T. Sumida, N. Doi, and H. Yanagawa, "Bicistronic DNA display for in vitro selection of Fab fragments," Nucleic Acids Research, vol. 37, no. 22, Article ID gkp776, p. e147, 2009.

[12] Y. Tay, C. Ho, P. Droge, and F. J. Ghadessy, "Selection of bacteriophage lambda integrases with altered recombination specificity by in vitro compartmentalization," Nucleic Acids Research, vol. 38, no. 4, article e25, 2010.

[13] L. Wang and P. G. Schultz, "A general approach for the generation of orthogonal tRNAs," Chemistry and Biology, vol. 8, no. 9, pp. 883-890, 2001.

[14] N. Kotlova, T. M. Ishii, E. I. Zagryadskaya, and S. V. Steinberg, "Active suppressor tRNAs with a double helix between the Dand T-loops," Journal of Molecular Biology, vol. 373, no. 2, pp. 462-475, 2007.

[15] A. Frankel and R. W. Roberts, "In vitro selection for sense codon suppression," RNA, vol. 9, no. 7, pp. 780-786, 2003.

[16] H. Taira, T. Hohsaka, and M. Sisido, "In vitro selection of tRNAs for efficient four-base decoding to incorporate nonnatural amino acids into proteins in an Escherichia coli cellfree translation system," Nucleic Acids Research, vol. 34, no. 5, article e44, 2006.

[17] D. Lipovsek and A. Plückthun, "In-vitro protein evolution by ribosome display and mRNA display," Journal of Immunological Methods, vol. 290, no. 1-2, pp. 51-67, 2004. 
[18] A. Ogawa, S. Sando, and Y. Aoyama, “Termination-free prokaryotic protein translation by using anticodon-adjusted $E$. coli tRNA $^{\text {Ser }}$ as unified suppressors of the UAA/UGA/UAG stop codons. Read-through ribosome display of full-length DHFR with translated UTR as a buried spacer arm," ChemBioChem, vol. 7, no. 2, pp. 249-252, 2006.

[19] Y. Shimizu, A. Inoue, Y. Tomari et al., "Cell-free translation reconstituted with purified components," Nature Biotechnology, vol. 19, no. 8, pp. 751-755, 2001.

[20] J. Normanly, T. Ollick, and J. Abelson, "Eight base changes are sufficient to convert a leucine-inserting tRNA into a serine-inserting tRNA," Proceedings of the National Academy of Sciences of the United States of America, vol. 89, no. 12, pp. 5680-5684, 1992.

[21] G. Eggertsson and D. Söll, "Transfer ribonucleic acid-mediated suppression of termination codons in Escherichia coli," Microbiological Reviews, vol. 52, no. 3, pp. 354-374, 1988.

[22] J. R. Sampson and M. E. Saks, "Contributions of discrete tRNA $^{\text {Ser }}$ domains to aminoacylation by E.coli seryl-tRNA synthetase: a kinetic analysis using model RNA substrates," Nucleic Acids Research, vol. 21, no. 19, pp. 4467-4475, 1993.

[23] H. Murakami, A. Ohta, and H. Suga, "Bases in the anticodon loop of tRNAGGCAla prevent misreading," Nature Structural and Molecular Biology, vol. 16, no. 4, pp. 353-358, 2009.

[24] R. W. Roberts and J. W. Szostak, "RNA-peptide fusions for the in vitro selection of peptides and proteins," Proceedings of the National Academy of Sciences of the United States of America, vol. 94, no. 23, pp. 12297-12302, 1997.

[25] N. Nemoto, E. Miyamoto-Sato, Y. Husimi, and H. Yanagawa, "In vitro virus: bonding of mRNA bearing puromycin at the 3 -terminal end to the C-terminal end of its encoded protein on the ribosome in vitro," FEBS Letters, vol. 414, no. 2, pp. 405-408, 1997. 

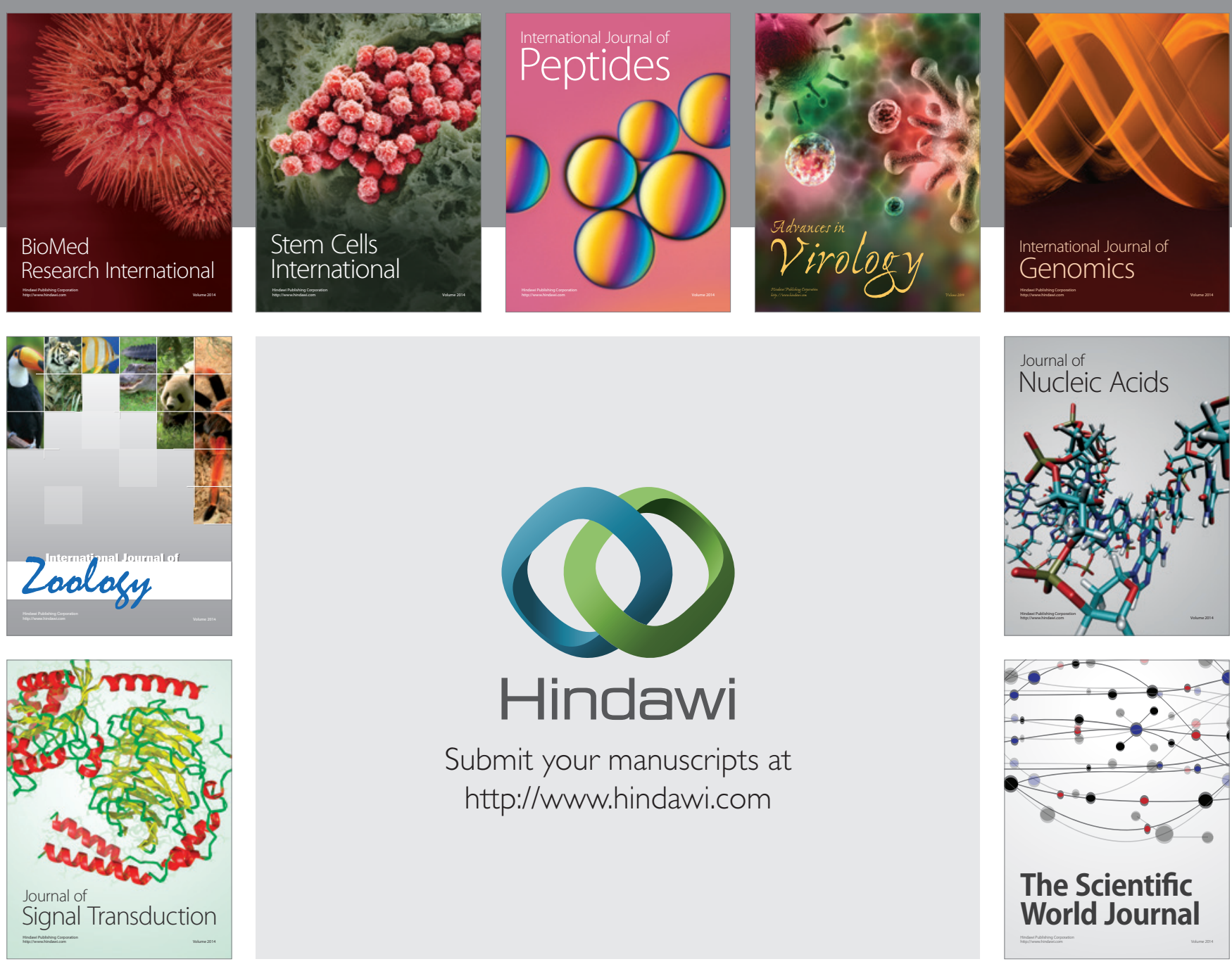

Submit your manuscripts at

http://www.hindawi.com
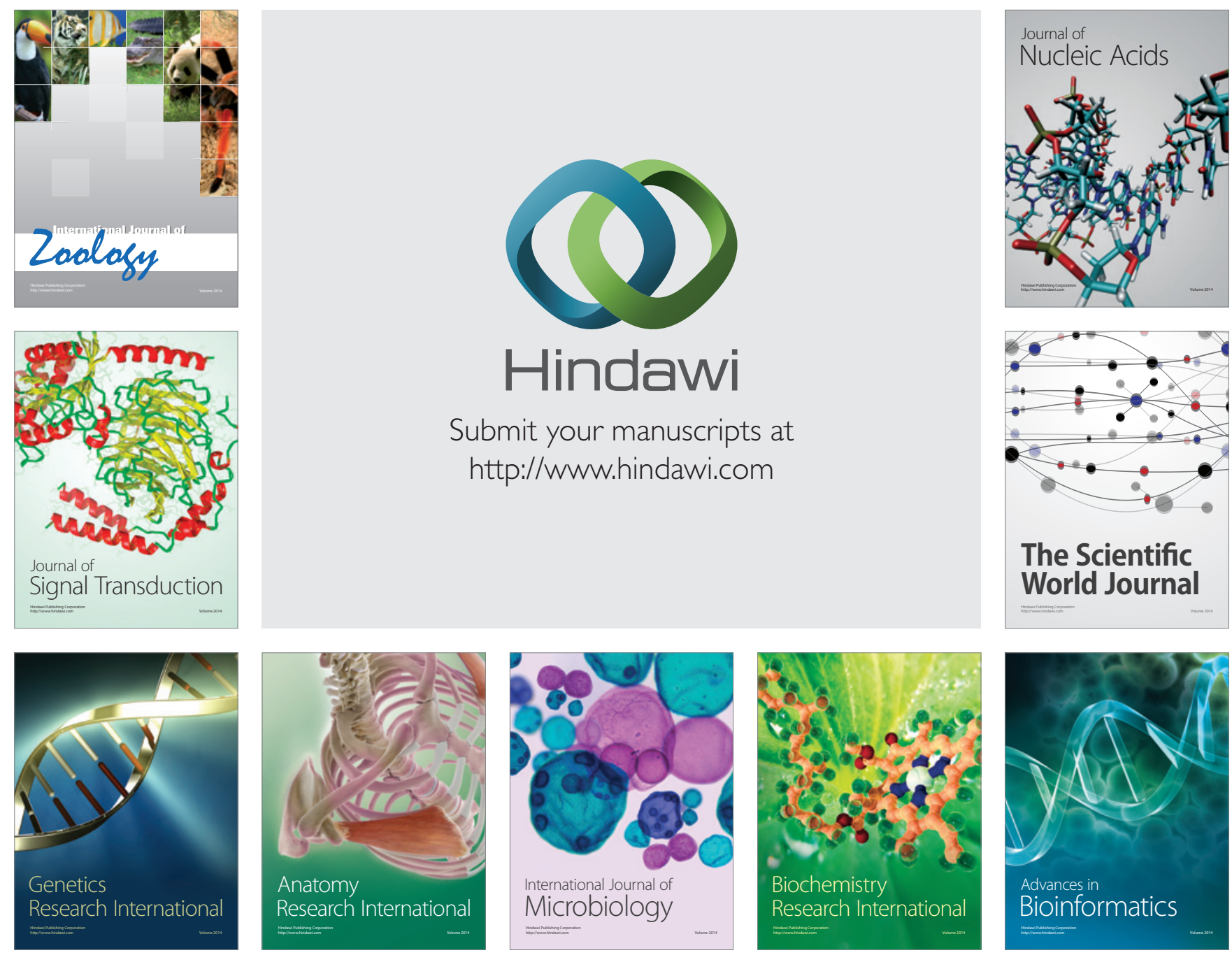

The Scientific World Journal
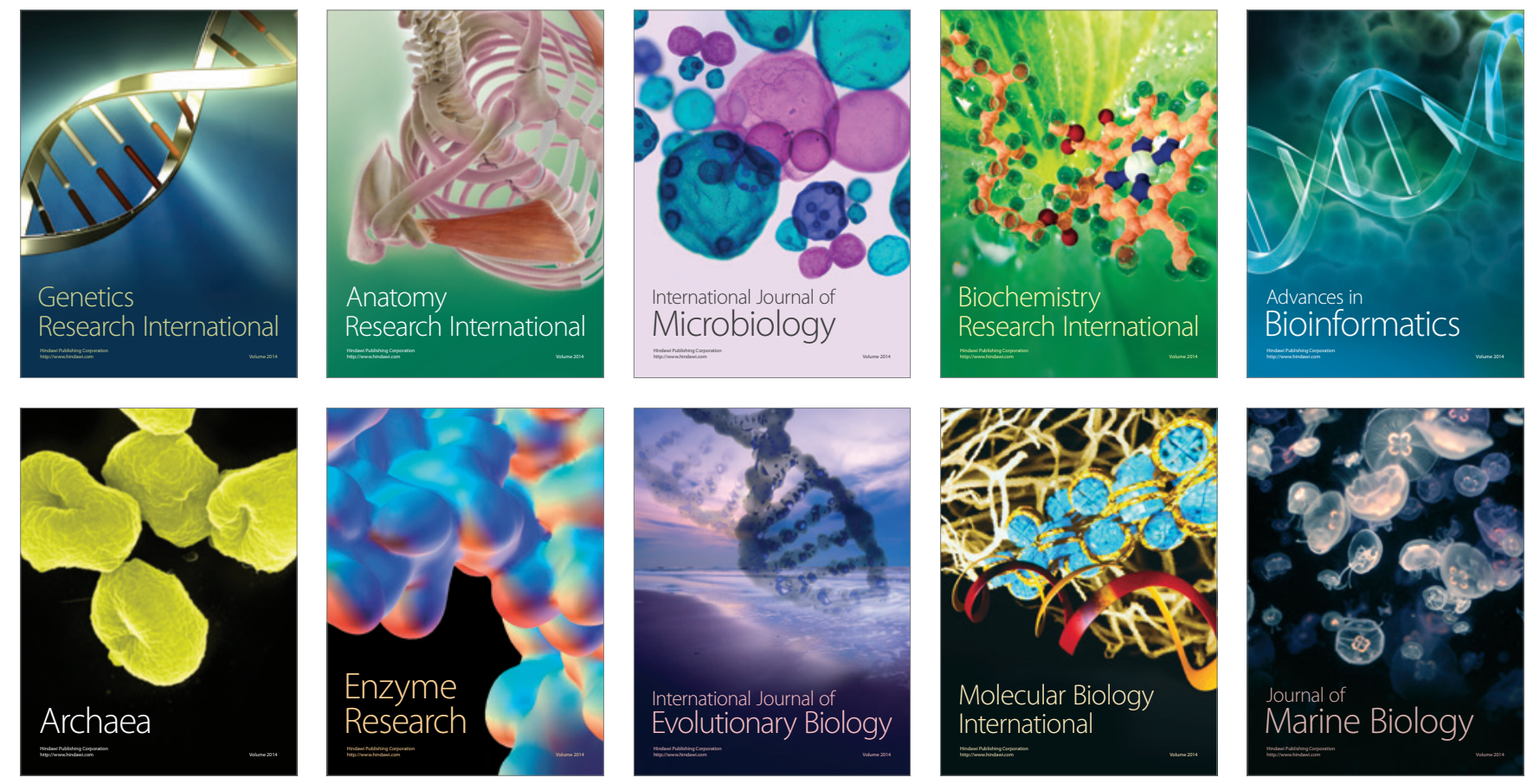